\title{
Comparison of PAHs uptake by selected Monocotyledones and Dicotyledones from municipal and industrial sewage sludge
}

\author{
Barbara Gworek $^{1} \cdot$ Katarzyna Klimczak $^{2} \cdot$ Marta Kijeńska $^{1} \cdot$ Dariusz Gozdowski $^{3}$
}

Received: 14 November 2015 / Accepted: 20 June 2016 / Published online: 6 July 2016

(C) The Author(s) 2016. This article is published with open access at Springerlink.com

\begin{abstract}
The study was focused on two goals: (i) the confirmation of the existence of a general relation between the content of polycyclic aromatic hydrocarbons (PAHs) in sewage sludge and in plants growing in it, regardless of the type and content of sewage sludge, and (ii) if so, the answer to the question whether the uptake of PAHs by plants depends on their type. To realize the set aims, the contents of PAHs in four differentiated plant species were measured, two belonging to the Monocotyledones and two belonging to Dicotyledones group, growing in municipal and industrial sewage sludge in two locations. All the investigations were carried out during the period of 3 years. The results clearly demonstrated that the uptake of PAHs by a plant depended on polyaromatic hydrocarbon concentration in the sewage sludge. The relation between accumulation coefficient of PAHs in plant material vs. the content of PAH in sewage sludge was of exponential character. The results indicate that in case of four- and five-ring PAHs, the root uptake mechanism from soil solution occurs, regardless of the type and origin of sewage sludge and the type of plant. For three-ring PAHs, we can assume for Monocotyledones that the root uptake mechanism occurs because we observe a significant correlation between the content
\end{abstract}

Responsible editor: Philippe Garrigues

Marta Kijeńska

marta.kijenska@ios.edu.pl

1 National Research Institute, Institute of Environmental Protection, Krucza 5/11 d, Warsaw, Poland

2 Department of Soil Environment Sciences, Warsaw University of Life Sciences-SGGW, Nowoursynowska 159, Warsaw, Poland

3 Department of Experimental Design and Bioinformatics, Warsaw University of Life Sciences - SGGW, Nowoursynowska 159, Warsaw, Poland of fluorene, phenanthrene, and anthracene in plant material and in the sewage sludge. For Dicotyledones, the correlation is insignificant, and in this case probably two mechanisms occur - the uptake by roots and by leaves.

Keywords PAHs · Root uptake $\cdot$ Sewage sludge $\cdot$ Dicotyledones $\cdot$ Monocotyledones

\section{Introduction}

Polycyclic aromatic hydrocarbons (PAHs) are environmental contaminants and constitute the largest class of suspected carcinogens and mutagens (van Metre and Mahler 2003). They appear in the environment and originate from natural sources (like forest fires), but most of their emission is connected with human activity (Benner and Gordon 1989; Garcia et al. 2012; Harvey et al. 2002; Lim et al. 1999; Weisman et al. 2010; Wild and Jones 1995) or, sometimes, human activity influences the mobility of PAHs in the environment (Zuijdgeest and Huettel 2012). They are known in particular as air contaminants occurring in places exposed to combustion smoke and situated near large urban centers (Arruti et al. 2012; De Nicola et al. 2005; Nielsen 1996). An additional source of emission of these compounds is cigarette smoking (Choi et al. 2010). They have special molecular structure - whole molecule is of aromatic character without substituents which is responsible for significant potential of interference with living organisms. The most studied and most known compound of the group is benzo[a]pyrene (Dutta et al. 2010), but it is to highlight that PAH compounds never exist alone - they always occur in a mixture, which was confirmed in many experiments (Mumtaz and George 1995).

It is proven that respiratory or dietary exposure to or skin contact with substances containing PAH mixtures causes lung 
cancer and tumors. That is why benzo[a]anthracene, benzo[a]pyrene, benzo[b]fluoranthene, benzo[j]fluoranthene, benzo[k]fluoranthene, dibenz[a,h]anthracene, and indeno[1,2,3-cd]pyrene were classified by the Department of Health and Human Services (DHHS) as known animal carcinogens (Mumtaz and George 1995). The International Agency for Research on Cancer (IARC) classified benzo[a]pyrene as human carcinogen (group 1), and some PAHs are classified as probable human carcinogens (group 2A) and or possible human carcinogens (group 2B) (IARC Monograph 2010).

As mentioned above, it is very difficult to assess the influence of PAHs' presence in dietary exposure on living organisms. Nevertheless, the fact that they are carcinogenic for animals and due to some novel proofs that not only respiratory but also dietary exposure to PAHs may be carcinogenic for humans (Lee and Shim 2007; Yoon et al. 2007) raised the question whether PAHs accumulated in vegetables may develop different forms of cancer. The answer seems to be positive (Ashraf et al. 2013).

Considering the above, it is very important to define the pathway of the uptake of PAHs from sewage sludge to plants which is decisive for their content in plant material. Also of great importance is to find the relationship between polyaromatic hydrocarbon structure and the efficiency of their uptake by plants, i.e., which of the hydrocarbons are most easily accumulated by plants from a sewage sludge. Two mechanisms of the accumulation of PAHs by plants are taken under consideration. According to the first one, the transfer of PAHs from polluted atmosphere to plants occurs via particlephase deposition on the waxy leaf cuticle or by the uptake from the gas phase through stomata (Duarte-Davidson and Jones 1996; Meudec et al. 2006). The second one assumes the root uptake from the soil solution and the liquid phase transfer in the transpiration streams (Duarte-Davidson and Jones 1996; Gao and Zhu 2004; Meudec et al. 2006; Yang and Zhu 2007; Zhu and Gao 2004).

There are numerous papers considering the influence of PAHs present in air on the development of cancer (Armstrong et al. 2004; Bosetti et al. 2007; Jung et al. 2010; Mastrangelo et al. 1996; Ravindra et al. 2001). Several regulations were prepared indicating the acceptable content of PAHs in the air, water, and soil. However, only very few studies take into account the influence of PAH content in plant and animal commodities on the human health. Also, a lack of norms regulating the content of PAHs in market products should be underlined.

Since the second half of the 1980s of the twentieth century (e.g., the Directive 86/278/EEC), there is a visible trend in the European Union jurisdiction to allow the utilization of sewage sludge, which always contains significant quantities of PAHs, as a natural fertilizer in the agriculture. This enhances the necessity to answer the question, if there is a correlation between the content of PAHs in sewage sludge and their concentration in a plant growing in it. The studies on the content of PAHs in sewage sludge and the changes of PAHs during sewage sludge composting were conducted by Oleszczuk (2007), but they are not devoted to the bioavailability of PAHs in sewage sludge. There are some studies about bioavailability of PAHs in soils (Guo et al. 2016; Lal et al. 2015), but it can be additional information only. The aim of our research was to check the influence of sewage sludge on PAH content in plants under natural conditions. Most studies on contaminants like PAHs are conducted under greenhouse conditions or in pots (Chen et al. 2016; Wieczorek et al. 2015). This study was conducted during 3 years on plants growing spontaneously on sewage sludge lagoon. Such approach can make the conclusions from the study more realistic and make the conclusions valuable for predicting possible contamination with PAHs in food or feed of plant origin.

The results of our previous research (Gworek et al. 2014) demonstrated the appearance of a strong correlation between the concentration of PAHs in sewage sludge and in plants growing in it.

The present study was focused on two goals: (i) the confirmation of the existence of a general relation between the content of PAHs in sewage sludge and in plants growing in it, irrespective of the type and content of sewage sludge, and (ii) if so, the answer to the question, whether the uptake of PAHs from the ground depends on the type of plant.

To realize the set aims, the contents of PAHs in four differentiated plant species were measured, two belonging to the Monocotyledones and two belonging to the Dicotyledones group, growing in municipal and industrial sewage sludge in two locations. All the analyses were carried out during the period of 3 years.

\section{Materials and methods}

\section{Sampling}

Two sewage sludge lagoons, one situated near a refinerypetrochemistry complex (location 1-L1) and one in an urban area (location 2-L2), were selected for this study. At each site, the samples of sewage sludge and of plant material growing in it had been collected for 3 years. In the sewage sludge and in plant material, the concentrations of 13 of the PAHs listed on US EPA specification (Zhou and Zhao 2014) were estimated.

\section{Characteristics of sampling sites and locations}

\section{Location 1-sewage-treatment plant}

In the chosen location, there is one lagoon with sewage sludge of petrochemical origin from the integrated refinery- 
petrochemistry complex. The refinery part of the complex processes crude oil to fuels (gasoline, diesel oil, jet fuel, etc.), as well as to other oil fractions (e.g., boiler fuel) and to olefins (ethylene, propylene, $\mathrm{C}_{4}$ fraction), while the petrochemical sector produces a wide scale of basic chemicals (ethylene oxide, phenol, benzene, toluene, xylenes, etc.). During crude oil processing, various hydrocarbon fractions are formed, some of which as volatile organic compounds are contaminations emitted as the so-called "low emission" into the atmosphere. Others, such as stable organic contaminations, are collected on sludge lagoons and stored there.

In the refinery-petrochemistry complex, some technologies were adopted, allowing for the reduction of PAH content in the sewage sludge carried onto a lagoon. All wastewater is treated in a four-stage cycle: mechanical treatment; biological treatment and rainwater drainage; accelerators and rainwater drainage; and algal and reed ponds and rainwater drainage. Moreover, on the plant premises, there are 21 local pretreatment plants linked with respective units.

The sewage sludge originating from waste treatment in the refinery complex was stored on a field of a surface area amounting to ca. 10 ha. General characteristics of sewage sludge are as follows: $\mathrm{pH} 7.80-8.14$, organic matter 29.08$35.20 \%$, and nitrogen content $2.44-2.51 \%$.

\section{Location 2-municipal sewage-treatment plant}

Location 2 is a small town of 11,000 inhabitants. The municipal sewage plant treated living household wastes and sewage from small-scale industry. All wastewater is treated in a twostage process. The first phase is filtration, the second one is aeration tank. The sludge in the municipal sewage treatment plant in L2 was stored on four lagoons, each one of the surface area of $1500 \mathrm{~m}^{2}$. General characteristics of sewage sludge are as follows: $\mathrm{pH} 4.51-6.41$, organic matter $39.21-75.20 \%$, and nitrogen content $0.15-0.88 \%$.

From each sampling site, the samples of sewage sludge and plants growing in it had been collected for 3 years. The sewage sludge from each lagoon was collected separately-from each lagoon, eight samples were taken and joined into a mixed sample.

The four plant species were found in both locationscouch grass (Agropyron repens), wood small-reed (Calamagrostis epigejos), wild buckwheat (Polygonum convolvulus), and white goosefoot (Chenopodium album). The first two of them belong to the family of Monocoty ledones and the last two to the Dicotyledones.

The plant samples included the dominating species of plants, as well as the accompanying species. According to the assumptions of the present study, the same plant species had to be collected in all study fields. Significant differentiation in the humidity of the base at various lagoons made it impossible in some cases.

\section{Methods}

The samples used for the analyses were dried in a laminar chamber at room temperature (about $25^{\circ} \mathrm{C}$ ) during a few days for plants to 1 week for sludge. Consecutively, the dried substance was comminuted in a laboratory mill (plant samples) or grinded in a mortar (sludge samples). Sludge samples were subsequently screened on a sieve of $1 \mathrm{~mm}$ mesh. Due to the fact that the intention was to check if the usage of sewage sludge influenced PAH concentration in feeding staff, the concentration of PAHs was measured only in aerial parts of plants. Roots were not investigated. It allowed also to avoid the overestimation of PAH content caused by the absorption of PAHs onto roots.

\section{The analyses of PAHs}

The concentrations of 13 PAHs were evaluated, including the following:

three-ring (fluorene $(\mathrm{Frn})$, phenanthrene $(\mathrm{Ph})$, anthracene (A)); four-ring (fluoranthene (Ftn), pyrene (P), benzo[a] anthracene $(\mathrm{BaA})$, chrysene $(\mathrm{Ch}))$; five-ring (benzo[b]fluoranthene $(\mathrm{BbF})$, benzo[k]fluoranthene $(\mathrm{BkF})$, benzo[a]pyrene $(\mathrm{BaP})$, dibenz[a,h]anthracene $(\mathrm{DahA}))$; and six-ring (benzo[g,h,i]perylene (BghiP), indeno[1,2,3c,d]pyrene (IP)).

The following procedure was applied for the analysis of sewage sludge and plant material samples: $10 \mathrm{~g}$ of air-dried and grinded material was mixed with $50 \mathrm{~cm}^{3}$ of methylene chloride and extracted in the presence of metallic copper in Soxtec apparatus during $3.5 \mathrm{~h}$ and subsequently washed during $1.5 \mathrm{~h}$; the extracts were then concentrated to dried residue in a vacuum rotary evaporator; the dried residues were dissolved in $1-\mathrm{ml} \mathrm{n}$-hexane portions and introduced to the column of $10 \mathrm{~mm}$ diameter filled with silica gel (10 cm layer) and basic alumina oxide (10 $\mathrm{cm}$ layer); the column was washed with methylene chloride-n-hexane solution of a concentration ratio gradually changing from $1: 3$ to $1: 1$, the eluate was concentrated to dry residue under nitrogen, and consecutively $2 \mathrm{ml}$ of acetonitrile and $1 \mathrm{ml}$ of $\mathrm{n}$-hexane were added to the solid residue; and an aliquot of $10 \mu \mathrm{l}$ sampled from the acetonitrile layer was diluted in $5 \mathrm{ml}$ acetonitrile and $10 \mu \mathrm{l}$ was injected by hand into the chromatograph.

The content of the examined polyaromatic hydrocarbons was determined by means of high-pressure liquid chromatography (HPLC) with photodiode (PDA) and fluorescent (FLD) detectors. Qualitative and quantitative analysis was performed using the FLD detector while the PDA detector was used mostly to confirm identification of PAHs in samples using UV spectra.

The qualitative analysis of each hydrocarbon using the FLD detector was based on retention time and different lengths of emission and extinction waves. Estimation of 
quantitative analysis was performed on a base of signals (peak area) by method of calibration curve (determination coefficient $r^{2}$ was in the range 0.995-0.999) using capillary column SUPELCOSIL LC-PAH C18, S-5 $\mu \mathrm{m}, 15 \mathrm{~cm} \times 4.6 \mathrm{~mm}$. Ten microliters of sample was injected onto the capillary column, and separation was performed at $30{ }^{\circ} \mathrm{C}$ using gradient $50 \%$ acetonitrile and $50 \%$ water for $22 \mathrm{~min}$ to $100 \%$, followed by isocratic conditions for $36 \mathrm{~min}$. The validation method was performed on reference materials of sewage sludge and the standard addition method for plants. Detection limit of the method was determined at $0.03 \mathrm{ng} \mathrm{g}^{-1}$ for all investigated PAHs analyzed together at the same time, which corresponds to $0.000180 \mu \mathrm{mol} / \mathrm{kg}$ for fluorene; $0.000168 \mu \mathrm{mol} / \mathrm{kg}$ for anthracene and phenanthrene; $0.000148 \mu \mathrm{mol} / \mathrm{kg}$ for fluoranthene and pyrene; $0.000131 \mu \mathrm{mol} / \mathrm{kg}$ for benzo[a]anthracene and chrysene; $0.000119 \mu \mathrm{mol} / \mathrm{kg}$ for benzo[b]fluoranthene, benzo[k]fluoranthene, and benzo[a]pyrene; $0.000108 \mu \mathrm{mol} / \mathrm{kg}$ for dibenz[a,h]anth racene; and $0.000109 \mu \mathrm{mol} / \mathrm{kg}$ for benzo[g,h,i]perylene and indeno[1,2,3-c,d]pyrene. The average relative standard deviation for chromatographic analysis was $10 \%$, and the average expanded uncertainty of method with $95 \%$ confidence interval multiplied by the coverage factor $\mathrm{k}=2$ was about $30 \%$. The results were calculated taking into account the recovery value, which was in the range of 70-120\%.

The relation between the content of various PAHs in sewage sludge compared with the content in the plant growing in it was determined by the molar accumulation coefficient (m.a.c.) according to the following formula:

m.a.c. $=n_{p} / n_{s}$

where $n_{p}$ is the content of PAHs in plant material $(\mu \mathrm{mol} / \mathrm{kg})$ and $n_{s}$ is the content of PAHs in sewage sludge ( $\left.\mu \mathrm{mol} / \mathrm{kg}\right)$.

The corresponding concentration of PAHs, their uptake by plants, and the accumulation coefficient were expressed as molar magnitudes which allowed their direct use in further kinetic deliberations or biological activity description of an additive character.

\section{Statistical analyses}

For the evaluation of variability of PAH content, means and range for each species and sewage sludge were calculated. Relations between the accumulation coefficient of PAH in plant material and the content of PAH in sewage sludge were estimated with the use of power function model of regression $\left(\mathrm{Y}=\mathrm{aX} \mathrm{X}^{\mathrm{b}}\right)$. The model was selected to maximize the coefficient of determination. The analyses were performed in Statgraphics 4.1 statistical software, and the figures were prepared in Microsoft Excel. Significance level for all analyses was set at 0.05 .

\section{Results}

In both chosen locations, the observations were carried out for 3 years and samples were collected from one field in location 1 and from four different fields in location 2.

The range of PAH concentration and their average values are presented in Table 1. The detected contents of PAHs for both locations under study differed remarkably. The sewage sludge in L1, located closely to the large industrial area, was cleaner and contained significantly lower amount of PAHs. A higher polyaromatic contamination was noted for L2, where only small industry appeared. This observation was most probably due to the much lower effectiveness of the municipal waste treatment station in L2 as compared with the industrial installation in L1. At the present state of the waste treatment procedures and technologies, the results of the above comparison denied the general belief that near-industrial areas are always more contaminated than municipal areas. The difference in the PAH content in both types of sewage sludge may be also connected to the significant difference in organic matter content in both types of sludge. The sewage sludge from L1 (industrial) had 29.08-35.20\% of organic matter and the sewage sludge from L2 (municipal) had $39.21-75.20 \%$ of organic matter. There is a well-known relationship between the organic matter content in soils/sediments and probably sludge and the PAH contamination level.

The determination of the content of PAHs in plants growing in the two investigated sewage sludge lagoons was the next step of our investigations. The four plant species were found in both locations - couch grass (Agropyron repens), wood small-reed (Calamagrostis epigejos), wild buckwheat (Polygonum convolvulus), and white goosefoot (Cheno podium album). The first two of them belong to the family of Monocotyledones and the last two to the Dicotyledones.

The range of PAH concentration in plant material for each particular species and their average values are demonstrated in Table 1. Phenanthrene was present in dominant amounts in all analyzed plant materials, irrespective of the content of PAHs in sewage sludge. The content of phenanthrene in plants fluctuated from $0.185 \mu \mathrm{mol} / \mathrm{kg}$ (for Chenopodium album collected in L2) to $0.348 \mu \mathrm{mol} / \mathrm{kg}$ (in Agropyron repens, collected in L2). Furthermore, the content of phenanthrene in the plant material seemed not to be related to the content of phenanthrene in the sewage sludge. The amount of phenanthrene in sewage sludge from L2 was two times higher than the one in L1 $(1.44 \mu \mathrm{mol} / \mathrm{kg}$ in L2 in comparison to $0.79 \mu \mathrm{mol} / \mathrm{kg}$ of phenanthrene in sewage sludge in L1), while the content of it in Agropyron repens and Calamagrostis epigejos was higher for the plant material collected in L2 and, oppositely, the content of phenanthrene in Chenopodium album and Polygonum convolvulus was higher for plant samples collected in L1.

In most cases, the second most widespread PAH in plants was fluoranthene $(0.115 \mu \mathrm{mol} / \mathrm{kg}$ in Chenopodium album 
Table 1 Means $(\mu \mathrm{mol} / \mathrm{kg}$ ) and range (min-max) for examined plant species and sewage sludge for both locations

\begin{tabular}{|c|c|c|c|c|c|c|}
\hline \multirow[t]{2}{*}{$\mathrm{PAH}$} & \multicolumn{2}{|l|}{ Dicotyledones } & \multicolumn{2}{|l|}{ Monocotyledones } & \multicolumn{2}{|c|}{ Sewage sludge } \\
\hline & $\begin{array}{l}\text { Chenopodium } \\
\text { album }(\mu \mathrm{mol} / \mathrm{kg})\end{array}$ & $\begin{array}{l}\text { Polygonum } \\
\text { convolvulus }(\mu \mathrm{mol} / \mathrm{kg})\end{array}$ & $\begin{array}{l}\text { Agropyron } \\
\text { repens }(\mu \mathrm{mol} / \mathrm{kg})\end{array}$ & $\begin{array}{l}\text { Calamagrostis } \\
\text { epigejos }(\mu \mathrm{mol} / \mathrm{kg})\end{array}$ & $\begin{array}{l}\text { Location } 1 \\
(\mu \mathrm{mol} / \mathrm{kg})\end{array}$ & $\begin{array}{l}\text { Location } 2 \\
(\mu \mathrm{mol} / \mathrm{kg})\end{array}$ \\
\hline Frn & $\begin{array}{l}0.101 \\
(0.04-0.202)\end{array}$ & $\begin{array}{l}0.106 \\
(0.085-0.157)\end{array}$ & $\begin{array}{l}0.119 \\
(0.087-0.188)\end{array}$ & $\begin{array}{l}0.134 \\
(0.07-0.178)\end{array}$ & $\begin{array}{l}0.24 \\
(0.18-0.34)\end{array}$ & $\begin{array}{l}0.34 \\
(0.81-2.05)\end{array}$ \\
\hline $\mathrm{Ph}$ & $\begin{array}{l}0.201 \\
(0.103-0.318)\end{array}$ & $\begin{array}{l}0.233 \\
(0.194-0.32)\end{array}$ & $\begin{array}{l}0.328 \\
(0.241-0.393)\end{array}$ & $\begin{array}{l}0.276 \\
(0.163-0.328)\end{array}$ & $\begin{array}{l}0.79 \\
(0.53-1.17)\end{array}$ & $\begin{array}{l}1.43 \\
(0.81-2.05)\end{array}$ \\
\hline A & $\begin{array}{l}0.015 \\
(0.009-0.023)\end{array}$ & $\begin{array}{l}0.018 \\
(0.009-0.036)\end{array}$ & $\begin{array}{l}0.022 \\
(0.014-0.042)\end{array}$ & $\begin{array}{l}0.022 \\
(0.007-0.036)\end{array}$ & $\begin{array}{l}0.17 \\
(0.01-0.43)\end{array}$ & $\begin{array}{l}0.30 \\
(0.11-0.60)\end{array}$ \\
\hline Ftn & $\begin{array}{l}0.127 \\
(0.067-0.174)\end{array}$ & $\begin{array}{l}0.125 \\
(0.094-0.171)\end{array}$ & $\begin{array}{l}0.177 \\
(0.118-0.23)\end{array}$ & $\begin{array}{l}0.142 \\
(0.097-0.176)\end{array}$ & $\begin{array}{l}0.71 \\
(0.30-1.51)\end{array}$ & $\begin{array}{l}3.14 \\
(0.71-4.71)\end{array}$ \\
\hline $\mathrm{P}$ & $\begin{array}{l}0.075 \\
(0.048-0.112)\end{array}$ & $\begin{array}{l}0.116 \\
(0.051-0.232)\end{array}$ & $\begin{array}{l}0.088 \\
(0.065-0.142)\end{array}$ & $\begin{array}{l}0.073 \\
(0.043-0.095)\end{array}$ & $\begin{array}{l}0.59 \\
(0.12-1.26)\end{array}$ & $\begin{array}{l}2.1 \\
(0.63-3.65)\end{array}$ \\
\hline $\mathrm{BaA}$ & $\begin{array}{l}0.008 \\
(0.007-0.012)\end{array}$ & $\begin{array}{l}0.011 \\
(0.005-0.027)\end{array}$ & $\begin{array}{l}0.017 \\
(0.008-0.038)\end{array}$ & $\begin{array}{l}0.007 \\
(0.003-0.01)\end{array}$ & $\begin{array}{l}0.15 \\
(0.04-0.36)\end{array}$ & $\begin{array}{l}1.2 \\
(0.27-3.01)\end{array}$ \\
\hline $\mathrm{Ch}$ & $\begin{array}{l}0.020 \\
(0.014-0.028)\end{array}$ & $\begin{array}{l}0.015 \\
(0.009-0.024)\end{array}$ & $\begin{array}{l}0.025 \\
(0.01-0.053)\end{array}$ & $\begin{array}{l}0.017 \\
(0.009-0.024)\end{array}$ & $\begin{array}{l}0.15 \\
(0.06-0.33)\end{array}$ & $\begin{array}{l}1.59 \\
(0.41-3.80)\end{array}$ \\
\hline $\mathrm{BbF}$ & $\begin{array}{l}0.013 \\
(0.009-0.019)\end{array}$ & $\begin{array}{l}0.010 \\
(0.007-0.013)\end{array}$ & $\begin{array}{l}0.013 \\
(0.008-0.018)\end{array}$ & $\begin{array}{l}0.011 \\
(0.005-0.017)\end{array}$ & $\begin{array}{l}0.64 \\
(0.50-0.74)\end{array}$ & $\begin{array}{l}2.1 \\
(0.36-3.80)\end{array}$ \\
\hline $\mathrm{BkF}$ & $\begin{array}{l}0.005 \\
(0.004-0.007)\end{array}$ & $\begin{array}{l}0.004 \\
(0.002-0.005)\end{array}$ & $\begin{array}{l}0.006 \\
(0.004-0.009)\end{array}$ & $\begin{array}{l}0.005 \\
(0.002-0.008)\end{array}$ & $\begin{array}{l}0.22 \\
(0.18-0.28)\end{array}$ & $\begin{array}{l}0.91 \\
(0.15-1.94)\end{array}$ \\
\hline $\mathrm{BaP}$ & $\begin{array}{l}0.010 \\
(0.008-0.014)\end{array}$ & $\begin{array}{l}0.007 \\
(0.004-0.009)\end{array}$ & $\begin{array}{l}0.014 \\
(0.006-0.027)\end{array}$ & $\begin{array}{l}0.008 \\
(0.002-0.014)\end{array}$ & $\begin{array}{l}0.54 \\
(0.41-0.66)\end{array}$ & $\begin{array}{l}1.83 \\
(0.32-3.26)\end{array}$ \\
\hline DahA & $\begin{array}{l}0.002 \\
(0.001-0.003)\end{array}$ & $\begin{array}{l}0.002 \\
(0.001-0.005)\end{array}$ & $\begin{array}{l}0.003 \\
(0.001-0.007)\end{array}$ & $\begin{array}{l}0.003 \\
(0.001-0.004)\end{array}$ & $\begin{array}{l}0.25 \\
(0.06-0.45)\end{array}$ & $\begin{array}{l}0.34 \\
(0.03-0.93)\end{array}$ \\
\hline BghiP & $\begin{array}{l}0.007 \\
(0.003-0.01)\end{array}$ & $\begin{array}{l}0.004 \\
(0.003-0.005)\end{array}$ & $\begin{array}{l}0.009 \\
(0.004-0.014)\end{array}$ & $\begin{array}{l}0.006 \\
(0.003-0.009)\end{array}$ & $\begin{array}{l}1.45 \\
(0.34-2.01)\end{array}$ & $\begin{array}{l}1.49 \\
(0.27-2.84)\end{array}$ \\
\hline IP & $\begin{array}{l}0.005 \\
(0.003-0.007)\end{array}$ & $\begin{array}{l}0.005 \\
(0.003-0.007)\end{array}$ & $\begin{array}{l}0.006 \\
(0.005-0.008)\end{array}$ & $\begin{array}{l}0.005 \\
(0-0.008)\end{array}$ & $\begin{array}{l}0.73 \\
(0.31-1.04)\end{array}$ & $\begin{array}{l}1.43 \\
(0.23-2.58)\end{array}$ \\
\hline
\end{tabular}

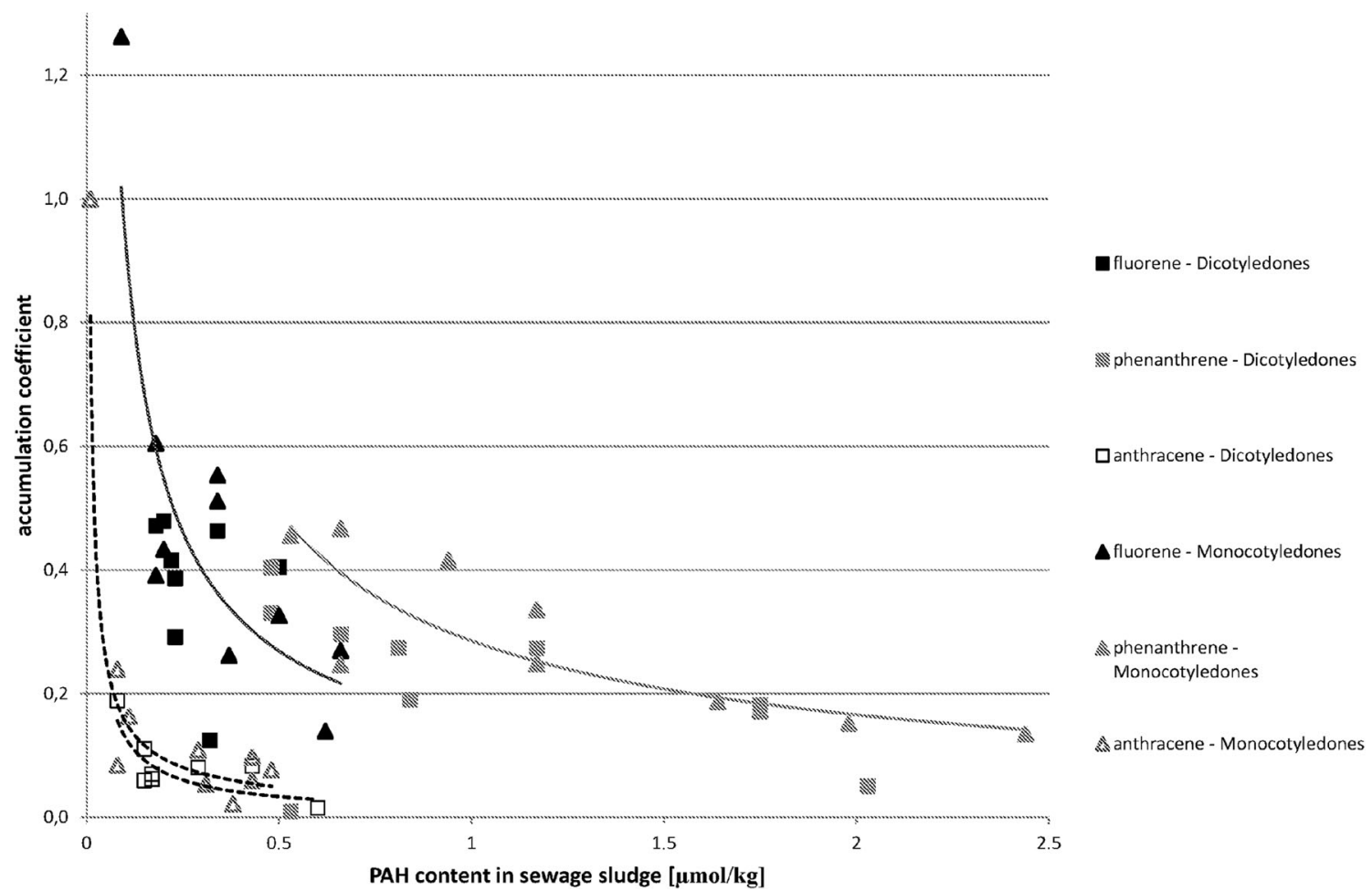

Fig. 1 The correlations between accumulation coefficient of PAH in plant material vs. the content of PAH in sewage sludge for three-ring hydrocarbons $(\mu \mathrm{mol} / \mathrm{kg})$ 
collected in L2 to $0.199 \mu \mathrm{mol} / \mathrm{kg}$ in Agropyron repens, collected in L2). The content of dibenz[ah]anthracene in plant material was the lowest in the entire series of PAHs (from $0.001 \mu \mathrm{mol} / \mathrm{kg}$ in Calamagrostis epigejos collected in L1 to $0.003 \mu \mathrm{mol} / \mathrm{kg}$ in Polygonum convolvulus collected in L1).

The analysis proved that in most cases there is a correlation between the content of PAHs in sewage sludge and in the plant material growing in it. The relation between the coefficient of $\mathrm{PAH}$ accumulation in plant material vs. the PAH content in sewage sludge is demonstrated in Fig. 1 for three-ring hydrocarbons, in Fig. 2 for four-ring hydrocarbons, in Fig. 3 for five-ring hydrocarbons, and in Fig. 4 for six-ring hydrocarbons. For all groups of hydrocarbons, the relation between $\mathrm{PAH}$ accumulation coefficient in plant material vs. the PAH content in sewage sludge was of exponential character.

\section{Discussion}

One of the questions formulated at the beginning of the experiment was if it is possible to predict and assess the estimated content of PAHs in plants knowing the content of PAHs in sewage sludge and if it is possible to compare the results irrespective of the type of sewage sludge, its origin, and its characteristics. That is why the results are presented together, irrespective of the municipal or petrochemical origin of sewage sludge. Both types of sewage sludge had different characteristics, which could affect the bioavailability of PAHs. There were several studies conducted in different types of soil (Lal et al. 2015) suggesting the influence of soil characteristics on PAH bioavailability. The studies conducted by Guo et al. on soils did not gave a clear answer (Guo et al. 2016). There is lack of studies conducted on sewage sludge. In our research, we did not observe the effect of sewage sludge properties on accumulation coefficient. The results of the regression analysis between $\mathrm{PAH}$ accumulation coefficient in plant material vs. the PAH content in sewage sludge are shown in Table 2. $P$ values below 0.05 indicate the existence of a significant correlation-for Monocotyledones, it appears for each PAH except indeno[123-cd]pyrene. For seven PAHs, the $P$ value was below 0.001 . In case of Dicotyledones, the $P$ values below 0.05 have been established for all four-, five-, and six-ring hydrocarbons. In the three-ring PAH series, for anthracene the estimated $P$ value was 0.030 , which means that there is a significant correlation, but for fluorene and phenanthrene the $P$ values were remarkably higher, 0.569 and 0.781 accordingly. As it was remarked earlier, two possible uptake mechanisms or their coexistence could be taken under consideration (Duarte-Davidson and Jones 1996; Gao and Zhu 2004; Meudec et al. 2006; Yang and Zhu 2007; Zhu and Gao 2004). It is very difficult to establish the primary source of PAH uptake by plants (Wieczorek et al. 2015). Even for plants growing in polluted soil, the mechanism of adsorption from gas-phase air may be a main source of PAHs, especially for

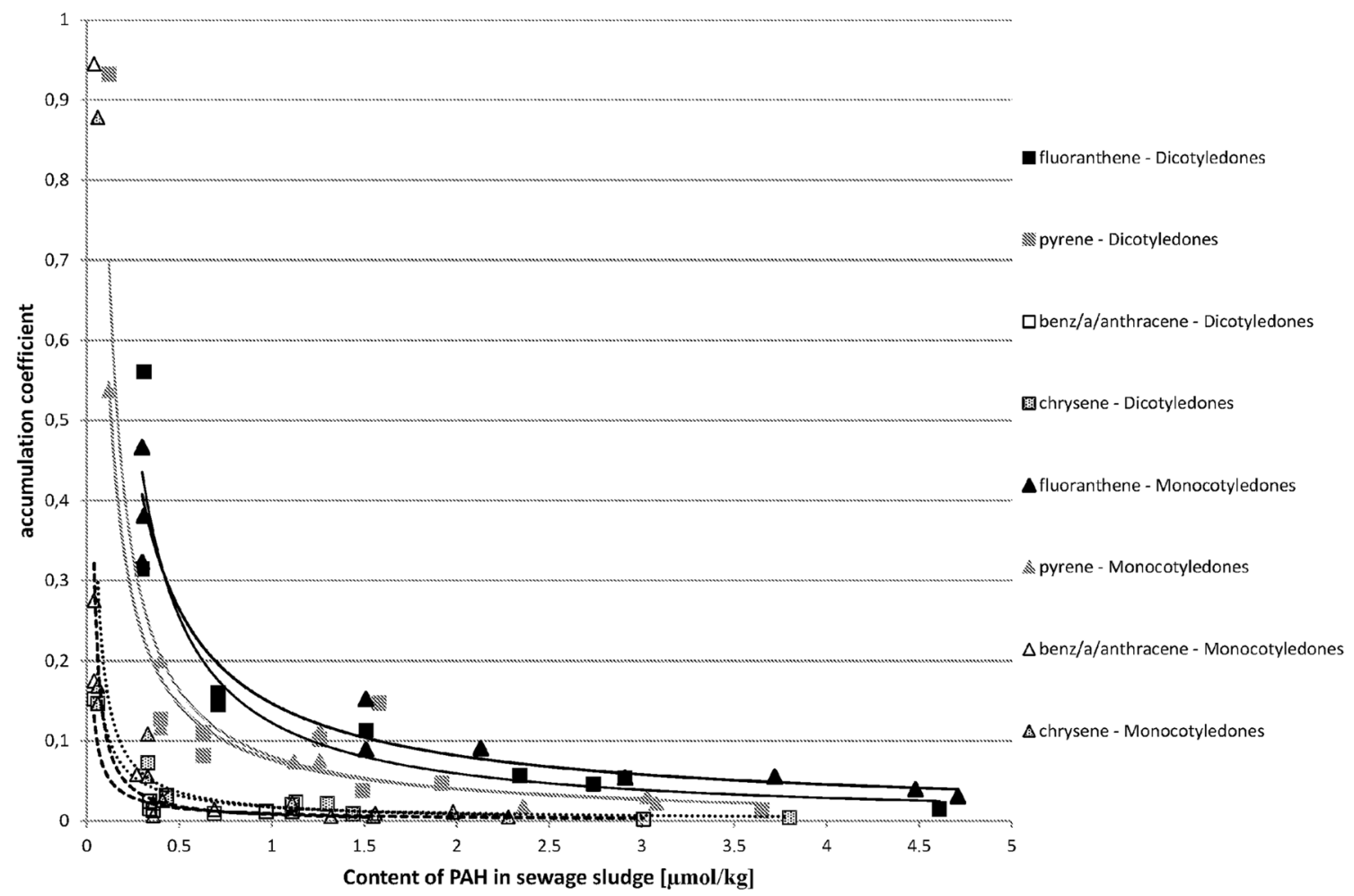

Fig. 2 The correlations between accumulation coefficient of PAH in plant material vs. the content of PAH in sewage sludge for four-ring hydrocarbons $(\mu \mathrm{mol} / \mathrm{kg})$ 


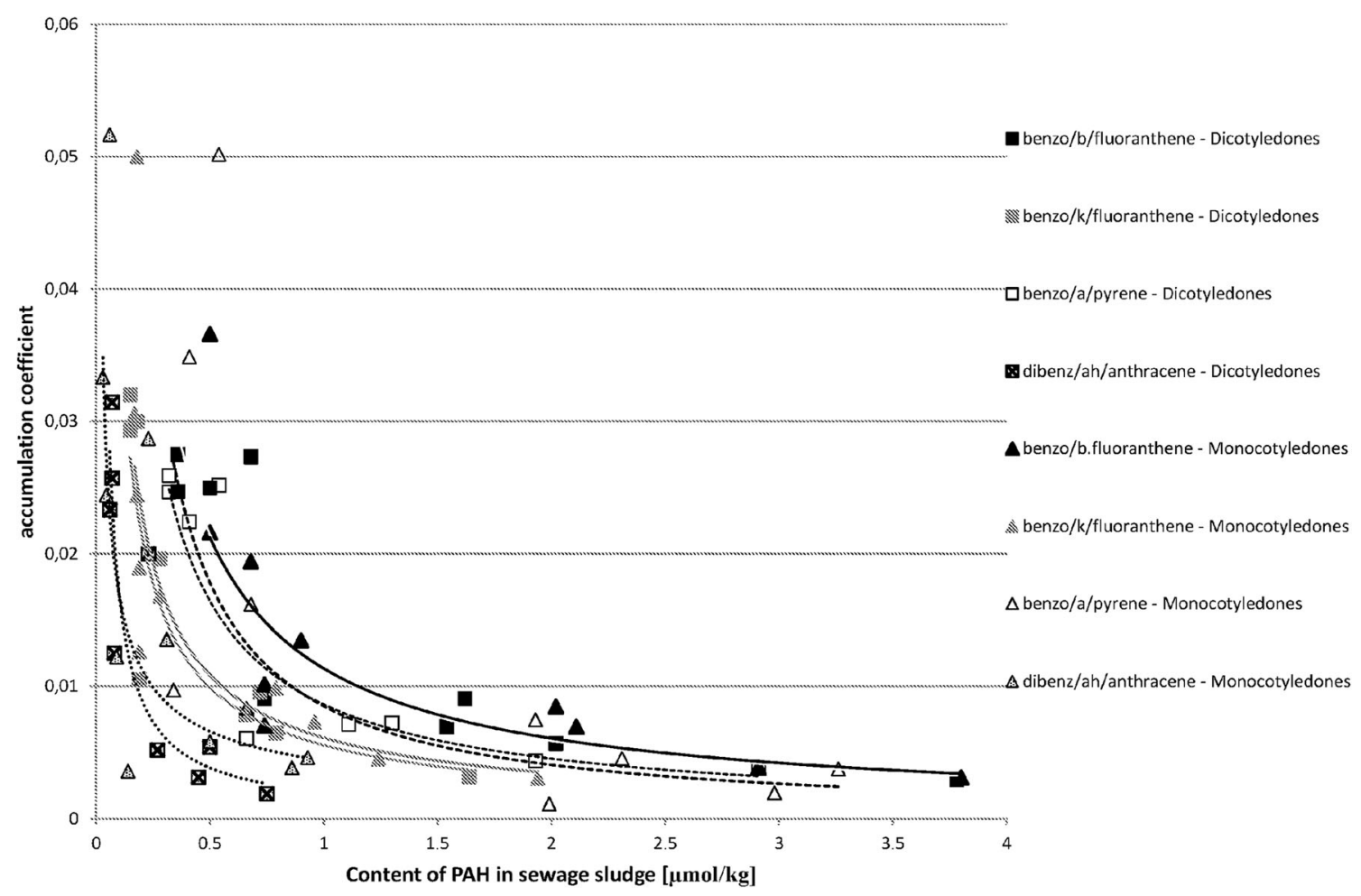

Fig. 3 The correlations between accumulation coefficient of PAH in plant material vs. the content of PAH in sewage sludge for five-ring hydrocarbons $(\mu \mathrm{mol} / \mathrm{kg})$

three-ring volatile compounds (Kaćalkova and Tlustoš 2011). Also, Kipopolou et al. reported the increase of lighter PAHs in above-ground parts of plants in summer (Kipopoulou et al. 1999). It was also demonstrated by Oishi that apart from the

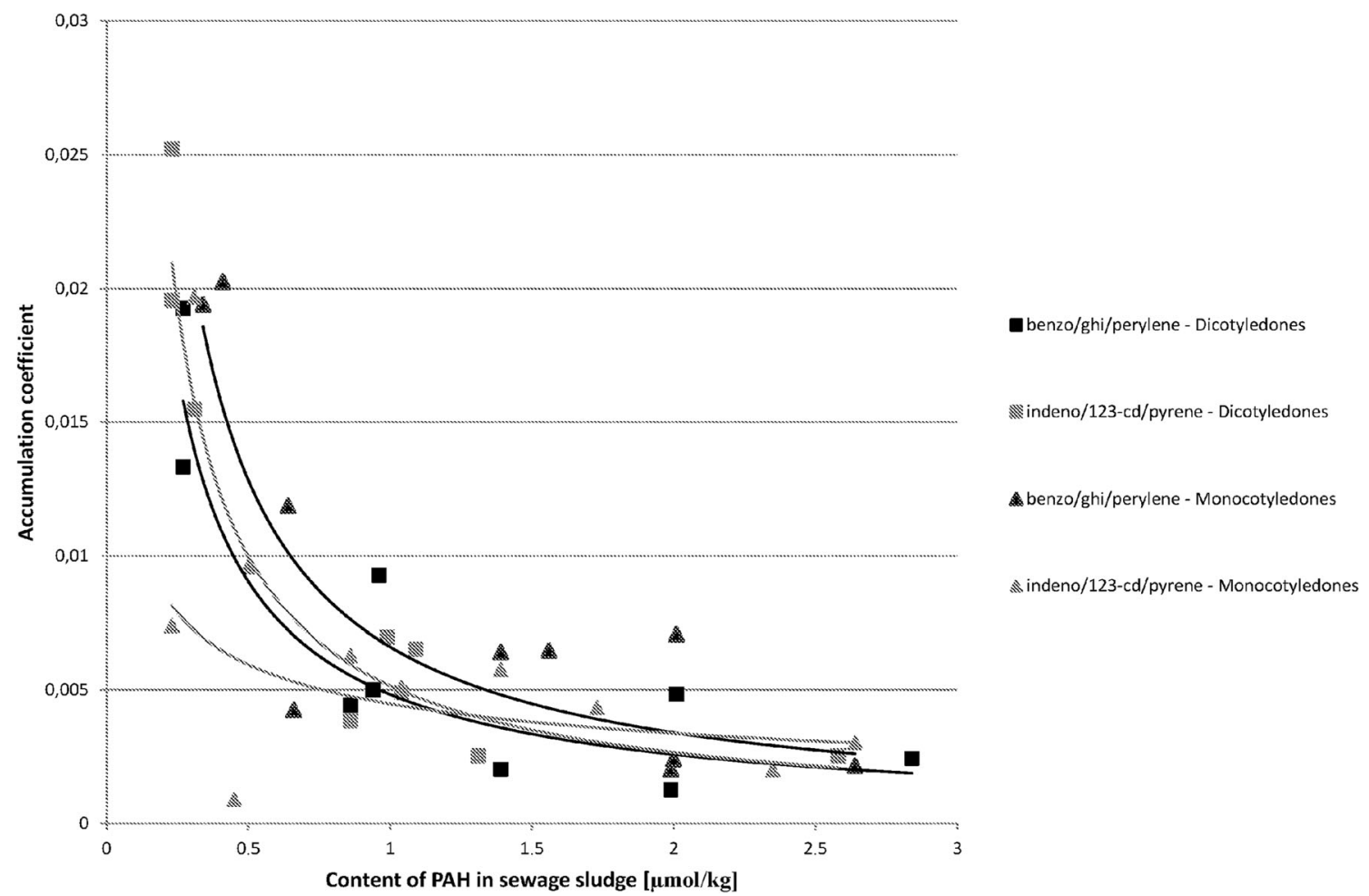

Fig. 4 The correlations between accumulation coefficient of PAH in plant material vs. the content of PAH in sewage sludge for six-ring hydrocarbons $(\mu \mathrm{mol} / \mathrm{kg})$ 
Table 2 Results of regression analysis between accumulation coefficient of PAH in plant material (Y) vs. the content of PAH in sewage sludge (X)

\begin{tabular}{|c|c|c|c|c|c|c|c|c|}
\hline & \multicolumn{4}{|c|}{ Dicotyledones $(n=9)^{\mathrm{a}}$} & \multicolumn{4}{|c|}{ Monocotyledones $(n=10)$} \\
\hline & $\mathrm{a}$ & $\mathrm{b}$ & $R^{2}$ & $P$ & $\mathrm{a}$ & $\mathrm{b}$ & $R^{2}$ & $P$ \\
\hline \multicolumn{9}{|l|}{ Three-ring hydrocarbons } \\
\hline Fluorene & 0.231 & -0.319 & 5.7 & 0.569 & 0.157 & -0.778 & 69.4 & 0.003 \\
\hline Phenanthrene & 0.149 & -0.240 & 1.2 & 0.781 & 0.285 & -0.786 & 76.5 & $<0.001$ \\
\hline Anthracene & 0.019 & -0.838 & 57.0 & 0.030 & 0.030 & -0.718 & 73.3 & 0.002 \\
\hline \multicolumn{9}{|l|}{ Four-ring hydrocarbons } \\
\hline Fluoranthene & 0.123 & -1.053 & 92.4 & $<0.001$ & 0.147 & -0.848 & 95.8 & $<0.001$ \\
\hline Pyrene & 0.081 & -1.019 & 78.7 & 0.001 & 0.076 & -0.932 & 89.1 & $<0.001$ \\
\hline Benzo[a]anthracene & 0.009 & -0.829 & 80.8 & 0.002 & 0.008 & -1.137 & 86.7 & $<0.001$ \\
\hline Chrysene & 0.017 & -0.837 & 90.9 & $<0.001$ & 0.018 & -1.002 & 86.2 & $<0.001$ \\
\hline \multicolumn{9}{|l|}{ Five-ring hydrocarbons } \\
\hline Benzo[b]fluoranthene & 0.011 & -0.934 & 87.9 & $<0.001$ & 0.011 & -0.905 & 77.3 & $<0.001$ \\
\hline Benzo[k]fluoranthene & 0.006 & -0.841 & 84.7 & $<0.001$ & 0.006 & -0.830 & 83.7 & $<0.001$ \\
\hline Benzo[a]pyrene & 0.009 & -0.930 & 83.6 & $<0.001$ & 0.008 & -1.069 & 59.9 & 0.009 \\
\hline Dibenz/ah/anthracene & 0.002 & -0.933 & 80.5 & 0.001 & 0.004 & -0.591 & 54.2 & 0.015 \\
\hline \multicolumn{9}{|l|}{ Six-ring hydrocarbons } \\
\hline Benzo[ghi]perylene & 0.005 & -0.906 & 71.7 & 0.004 & 0.007 & -0.959 & 69.0 & 0.003 \\
\hline Indeno[123-cd]pyrene & 0.005 & -0.956 & 88.8 & $<0.001$ & 0.004 & -0.408 & 16.5 & 0.245 \\
\hline
\end{tabular}

Applied regression model: $\mathrm{Y}=\mathrm{aX}$

$R^{2}$ coefficient of determination (\%), $P$ observed significance level for $F$ test, of which a value below 0.05 indicates significant correlation

${ }^{\mathrm{a}}$ In some cases, sample size was equal to 8 because of missing data

mechanism, where the plant takes up gaseous PAHs via its stomata, also the absorption of dissolved PAHs by leaves could occur (Oishi 2013). For four-ring and five-ring PAHs, the significant correlation between PAH accumulation coefficient in plant material vs. the PAH content in sewage sludge was observed. This supports the supposition that uptake of four- and five-ring PAHs occurs via roots. The correlation for four- and five-ring PAHs (Fig. 2 and 3) was observed irrespective of the compound, its origin, and its content in sewage sludge and also irrespective of the absorbing plant type. In the case of three-ring PAHs, the situation is differentiated depending on the plant type (Fig. 1). For Monocotyle dones, most probably the root uptake mechanism does occur, confirmed by the existence of a significant correlation between the content of fluorene, phenanthrene, and anthracene in plant material and in sewage sludge. For Dicotyledones, the observed correlation was insignificant. In this case, the mechanism of uptake by leaves could occur or two mechanisms could occur simultaneously - the uptake by roots and by leaves. Both studied plant species belonging to Monocotyle dones are characterized by very narrow leaves of small surface area, whereas the leaves of both studied species belonging to the group of Dicotyledones have a larger surface area. It cannot be excluded that three-ring PAHs are absorbed both by plants via roots and from the air via stomata (Meudec et al. 2006; Duarte-Davidson and Jones 1996). As volatile compounds, the three-ring polyaromatic hydrocarbons can be easily absorbed by plants from the air. These hydrocarbons can originally occur in the atmospheric air or appear by evaporation from sewage sludge. The question is why anthracene seemed to be taken up by roots both by Monocotyledones and Dicotyledones, as the only one three-ring PAH. It may be caused by its being different from the physicochemical properties of other three-ring PAHs. Older data indicated lower solubility of anthracene in water $(0.23-0.447 \mu \mathrm{mol} / \mathrm{L}$ in $\left.25^{\circ} \mathrm{C}\right)$ in comparison with phenanthrene $(5.58-9.0 \mu \mathrm{mol} / \mathrm{L}$ in $25^{\circ} \mathrm{C}$ ) (Pearlman et al. 1984). New sources show a reversed situation - solubility of anthracene in water $(73 \mu \mathrm{g} / \mathrm{L}$ in $25{ }^{\circ} \mathrm{C}$ ) seems to be higher than solubility of phenanthrene $\left(1.29 \times 10^{-3} \mu \mathrm{g} / \mathrm{L}\right.$ in $\left.25^{\circ} \mathrm{C}\right)$ and fluorene $\left(1.98 \times 10^{-3} \mu \mathrm{g} / \mathrm{L}\right.$ in $25^{\circ} \mathrm{C}$ ) (Gupta et al. 2015). Vapour pressure of these compound is also significantly different. It may be assumed that for easier soluble anthracene, the mechanism via root uptake may occur, which is confirmed in the significant correlation between the content of anthracene in sewage sludge and its accumulation coefficient. For phenanthrene and fluorene, which are more volatile and less soluble, the mechanism of uptake of PAHs via leaves from the air may occur, coexisting or not with the mechanism of uptake via root.

It is also unclear, why the significant correlation between the accumulation coefficient of indeno[123-cd]pyrene in the plant material vs. the PAH content in sewage sludge has been 
observed only for plants belonging to the Dicotyledones group (Fig. 4). This also needs further investigations. For benzo[ghi]perylene, the second analyzed aromatic hydrocarbon with six rings, a significant correlation between the accumulation coefficient in plant material vs. the content of it in sewage sludge was observed for both studied plant groups (Fig. 4).

Nevertheless, the existence of the correlation between the PAH content in plant material and in the substrate they are grown in seems to be unquestionnable. The correlation is of significant character without any doubts. The studies have to be continued for four- and five-ring PAH series. Most of polyaromatics influencing human health belong to this group. The following PAHs proved to have significant correlation, irrespective of the type of plant and the origin of the sewage sludge: benzo[a]pyrene, classified as human carcinogen (group 1); dibenz[ah]anthracene classified as probable human carcinogen (group 2A); and benzo[a]anthracene, benzo[b]fluoranthene, benzo[k]fluoranthene, and chrysene, classified as possible human carcinogens (group 2B).

\section{Conclusions}

The results of the experiment carried out on plants growing spontaneously on sewage sludge, under natural conditions simulating the agricultural uses, demonstrated that the uptake of PAHs by a plant depended on polyaromatic hydrocarbon concentration in sewage sludge. The relation between PAH accumulation coefficient in plant material vs. the PAH content in sewage sludge was of exponential character. The results indicate that for four- and five-ring PAHs, the root uptake mechanism from soil solution occurs, irrespective of the type and origin of sewage sludge and the content of PAHs in it and irrespective of the type of plant. A significant correlation was observed for both, Monocotyledones and Dicotyledones, and it did not depend on the municipal or petrochemical origin of sewage sludge the plants were growing in. For three-ring PAH absorption, the root uptake mechanism occurred in case of Monocotyledones, which is confirmed by the existence of a significant correlation between the content of fluorene, phenanthrene, and anthracene in plant material and in the sewage sludge. For Dicotyledones, the correlation is of insignificant character. In this case, probably two competitive mechanisms occur-the PAH uptake by roots and dissolved three-ring PAHs' absorption by leaves. The difference between the uptake of PAHs by two groups of plants was demonstrated also for six-ring PAHs. The correlation between the content of PAHs in sewage sludge and in plant material was significant for the Dicotyledones group. Further investigations are needed in order to explain why the correlation between the content of PAHs in sewage sludge and in plant material for Dicotyledones is significant for the group of four-, five-, and six-ring PAHs and in case of Monocotyledones for three-, four-, and five-ring PAHs. For the group of PAHs which is the most important and most dangerous to human health, fourand five-ring PAHs, which are the group including known human carcinogen such as benzo[a]pyrene, probable human carcinogen dibenz $[\mathrm{a}, \mathrm{h}]$ anthracene, and possible human carcinogens benzo[a]anthracene, benzo[b]fluoranthene, benzo[k]fluoranthene, and chrysene, the correlation between the content of PAHs in sewage sludge and in plant material was significant for both groups of plants, Monocotyledones and Dicotyledones, irrespective of the municipal or industrial origin of sewage sludge.

Open Access This article is distributed under the terms of the Creative Commons Attribution 4.0 International License (http:// creativecommons.org/licenses/by/4.0/), which permits unrestricted use, distribution, and reproduction in any medium, provided you give appropriate credit to the original author(s) and the source, provide a link to the Creative Commons license, and indicate if changes were made.

\section{References}

Armstrong B, Hutchinson E, Unwin J, Fletcher T (2004) Lung cancer risk after exposure to polycyclic aromatic hydrocarbons: a review and meta-analysis. Environ Health Perspect 112(9):970-978

Arruti A, Fernandez-Olmo I, Irabien A (2012) Evaluation of the urban/ rural particle-bond PAH and PCB levels in the northern Spain (Cantabria region). Environ Monit Assess 184:6513-6526

Ashraf MW, Taqvi SIH, Solangi AR, Qureshi UA (2013) Distribution and risk assessment of polycyclic aromatic hydrocarbons in vegetables grown in Pakistan. J Chem:1-5.

Benner B, Gordon G (1989) Mobile sources of atmospheric polycyclic aromatic hydrocarbons: a roadway tunnel study. Environ Sci Technol 23(10):1269-1278

Bosetti C, Boffetta P, La Vecchia C (2007) Occupational exposures to polycyclic aromatic hydrocarbons, and respiratory and urinary tract cancers: a quantitative review to 2005. Ann Oncol 18:431-446

Chen F, Tan M, Ma J, Zhang S, Li G, Qu J (2016) Efficient remediation of PAH-metal co-contaminated soil using microbial-plant combination: a greenhouse study. J Hazard Mater 302:250-261

Choi H, Harrison R, Komulainen H, Delgado Saborit JM (2010) Chapter 6: polycyclic aromatic hydrocarbons: $289-346$ in. WHO Guidelines for Indoor Air Quality: Selected Pollutants, Geneva, ISBN 97892 89002134.

De Nicola F, Maisto G, Prati MV, Alfani A (2005) Temporal variations in PAH concentrations in Quercus ilex L (holm oak) leaves in an urban area. Chemosphere 61:432-440

Duarte-Davidson R, Jones KC (1996) Screening the environmental fate of organic contaminants in sewage sludge applied to agricultural soils: II. The potential for transfers to plants and grazing animals. Sci Total Environ 185:59-70

Dutta K, Ghosh D, Nazmi A, Kumawat KL, Basu A (2010) A common carcinogen benzo[a]pyrene causes neuronal death in mouse via microglial activation. PLOS ONE 5(4): 1-14. Toxicological Profile for Polycyclic Aromatic Hydrocarbons (1995) US Department for Health and Human Services:1-458.

Gao Y, Zhu L (2004) Plant uptake, accumulation and translocation of phenanthrene and pyrene in soils. Chemosphere 55:1169-1178

Garcia R, Diaz-Somoano M, Calvo M, Lopez-Anton MA, Suarez S, Suarez Ruiz I, Martinez-Tarazona MR (2012) Impact of the semi- 
industrial coke processing plant in the surrounding surface soil. Part II: PAH content. Fuel Process Technol 104:245-252

Guo M, Gong Z, Allison G, Tai P, Miao R, Li X, Jia C, Zhuang J (2016) Variations in the bioavailability of polycyclic aromatic hydrocarbons in industrial and agricultural soils after bioremediation. Chemosphere 144:1513-1520

Gupta S, Pathak B, Fulekar MH (2015) Molecular approaches for biodegradation of polycyclic aromatic hydrocarbon compounds: a review. Rev Environ Sci Biotechnol 14:241-269

Gworek B, Klimczak K, Kijenska M (2014) The relation between polyaromatic hydrocarbon concentration in sewage sludge and its uptake by plants: Phragmites communis, Polygonum persicaria and Bidens tripartita. PLoS One 9(10):1-9

Harvey PJ, Campanella BF, Castro PML, Harms H, Lichtfouse E, et al. (2002) Phytoremediation of polyaromatic hydrocarbons, anilines and phenols. Environ Sci Pollut Res 9(1):29-47

IARC Monograph (2010): Some nonheterocyclic polycyclic aromatic hydrocarbons and some related exposures. IARC Monographs on the evaluation of carcinogenic risks to humans 92:1-853.

Jung KH, Yan B, Chillrud SN, Perera FP, Whyatt R, Camann D, Kinney PL, Miller RL (2010) Assessment of benzo(a)pyrene-equivalent carcinogenicity and mutagenicity of residential indoor versus outdoor polycyclic aromatic hydrocarbons exposing young children in New York City. Int J Environ Res Public Health 7:1889-1900

Kaćalkova L, Tlustoš P (2011) The uptake of persistent organic pollutants by plants. Cent Eur J Biol 6:223-235

Kipopoulou AM, Manoli E, Samara C (1999) Bioconcentration of polycyclic aromatic hydrocarbons in vegetables grown in an industrial area. Environ Pollut 106:369-380

Lal V, Peng C, Ng J (2015) A review of non-exhaustive chemical and bioavailability methods for the assessment of polycyclic aromatic hydrocarbons in soil. Environ Technol Innov 4:159-167

Lee BM, Shim GA (2007) Dietary exposure estimation of benzo[a]pyrene and cancer risk assessment. J Toxicol Environ Health A 70(15-16): 1391-1394

Lim L, Harrison R, Harrad S (1999) The contribution of traffic to atmospheric concentrations of polycyclic aromatic hydrocarbons. Environ Sci Technol 33(20):3538-3542

Mastrangelo G, Fadda E, Marzia V (1996) Polycyclic aromatic hydrocarbons and cancer in man. Environ Health Perspect 104(11):1166-1170

Meudec A, Dussauze J, Deslandes E, Poupart N (2006) Evidence for bioaccumulation of PAHs within internal shoot tissues by a halophytic plant artificially exposed to petroleum-polluted sediments. Chemosphere 65:474-481
Mumtaz M, George J (1995) Toxicological profile for polycyclic aromatic hydrocarbons , US Department for Health and Human Services:1-458.

Nielsen T (1996) Traffic contribution of polycyclic aromatic hydrocarbons in center of a large city. Atmos Environ 30:3481-3490

Oishi Y (2013) Comparison of pine needles and mosses as bio-indicators for polycyclic aromatic hydrocarbons. J Environ Prot 4:106-113

Oleszczuk P (2007) Changes of polycyclic aromatic hydrocarbons during composting of sewage sludges with chosen physico-chemical properties and PAHs content. Chemosphere 67:582-591

Pearlman RS, Yalkowsky SH, Banerjee S (1984) Water solubilities of polynuclear aromatic and heteraromatic compounds. J Phys Chem Ref Data 13:555-562

Ravindra K, Mittal AK, Van Grieken R (2001) Health risk assessment of urban suspended particulate matter with special reference to polycyclic aromatic hydrocarbons: a review. Rev Environ Health 16:169-189

van Metre PC, Mahler BJ (2003) The contribution of particles washed from rooftops to contaminant loading to urban streams. Chemosphere 52:1727-1741

Weisman D, Alkio M, Colon-Carmona A (2010) Transcriptional responses to polycyclic aromatic hydrocarbon-induced stress in Arabidopsis thaliana reveal the involvement of hormone and defense signaling pathways. BMC Plant Biol 10:59

Wieczorek J, Sienkiewicz S, Pietrzak M, Wieczorek Z (2015) Uptake and phytotoxicity of anthracene and benzo[k]fluoranthene applied to the leaves of celery plant (Apium graveolens var. secalinum L). Ecotoxicol Environ Saf 115:19-25

Wild SR, Jones KC (1995) Polynuclear aromatic hydrocarbons in the United Kingdom environment-a preliminary source inventory and budget. Environ Pollut 88:91-108

Yang Z, Zhu L (2007) Performance of the partition-limited model on predicting ryegrass uptake of polycyclic aromatic hydrocarbons. Chemosphere 67:402-409

Yoon E, Park K, Lee H, Yang JH, Lee C (2007) Estimation of excess cancer risk on time-weighted lifetime average daily intake of PAHs from food ingestion. Hum Ecol Risk Assess 13(3):669-680

Zhou B, Zhao B (2014) Analysis of intervention strategies for inhalation exposure to polycyclic aromatic hydrocarbons and associated lung cancer risk based on a Monte Carlo population exposure assessment model. PLoS One 9(1):1-11

Zhu L, Gao Y (2004) Prediction of phenanthrene uptake by plants with a partition-limited model. Environ Pollut 131:505-508

Zuijdgeest A, Huettel M (2012) Dispersants as used in response to the MC252-spill lead to higher mobility of polycyclic aromatic hydrocarbons in oil-contaminated Gulf of Mexico sand. PLoS One 7(11):1-13 